\title{
FREQUENCY OF PRENATAL DEPRESSION IN SECOND AND THIRD TRIMESTERS OF PREGNANCY IN KARACHI: A HOSPITAL BASED STUDY
}

\author{
M. Munir Hamirani, Azra Sultana, Zubeda Ibrahim, Humaira Iqbal and Sarwat Sultana
}

\begin{abstract}
OBJECTIVE: To determine the frequency of depression and its relationship with some demographic variables in pregnant women presenting in the second and third trimester at a tertiary care hospital in Karachi, Pakistan.

DESIGN: A descriptive study.

SETTING: Departments of Psychiatry and Gynecology/Obstetrics, Abbasi Shaheed Hospital, Karachi, Sindh- Pakistan, from July 2003 to October 2003.

METHODS: Seventy-five females in second and third trimester of pregnancy were interviewed in out patients department. Questionnaire was based on Edinburgh postnatal depression scale. Main outcome measure was to find out the number of pregnant depressed females.

RESULTS: Pregnant females had twenty-six to thirty-six weeks of pregnancy. Twenty-six females (34.6\%) were found to have clinically significant depression according to Edinburgh postnatal depression scale. Most of the cases were found between 22 and 36 weeks of pregnancy. The average age of presentation was 26 years. Six, out of $26(23 \%)$ depressed females were primigravida. More so, other cases which were having depression were mostly in their second or third confinements (ten cases out of twenty-six i.e. 38\%).

CONCLUSION: Prenatal depression is an important clinical entity and shall be screened during second and third trimesters of pregnancy. The more severe cases should be offered treatment with either psychotherapy or medications to avoid future complications.
\end{abstract}

KEY WORDS: Prenatal Depression. Edinburgh postnatal depression scale. Tertiary Care Hospital. Karachi.

\section{INTRODUCTION}

Depression is defined as the loss of pleasure or negative mood combined with a set of symptoms, which last more than two weeks and causes impairment in some or several areas of life. ${ }^{1}$ World Health Organization (WHO) predicts that depression will be the second greatest cause of premature death and disability worldwide by the year $2020 .^{2}$ WHO figures signal a worldwide epidemic of depression, affecting $>15 \%$ of the population and probably $>22 \%$ of women of childbearing age. ${ }^{3}$ A local study conducted on patients attending a community psychiatric clinic has showed high prevalence of various types of mental disorders like depression (51.9\%). ${ }^{4}$ In another study in Karachi, proportion of probable cases of maternal mental disorder has been reported $28.8 \%$. Approximately, 1 out of 4 women suffer from mental illness and it is alarmingly high. ${ }^{5}$ It is estimated that while more than $80 \%$ of women may experience some fluctuations in mood in either the prenatal period or postnatal, only 10 to $20 \%$ may meet diagnostic and statistical manual IV criteria (DSM-IV) for major depression. ${ }^{6}$ A study in Lahore has showed that females have a higher prevalence rate $(56 \%)$ of neurotic disorders on the basis of family problems and literacy rate as compared to the males $(43 \%){ }^{7}$ Untreated depression is associated with adverse fetal outcomes and a higher risk of maternal morbidity, including suicide ideation and attempts, and postnatal depression. ${ }^{8}$ Maternal depression affects the breast-feeding behavior of the mother. It causes mothers to stop breast-feeding their children. Pakistani women are under privileged and vulnerable during pregnancy. A prevalence of anxiety and depression among women in a lower middle class has been found $30 \%{ }^{9,10}$ Married females form the majority in this regard. ${ }^{11}$ Poverty, unemployment, abuses and on going difficulties were perceived as risk factors for depression. ${ }^{12}$ Only $23 \%$ of husbands belonging to lower socio-economic status accompany their wives to the hospital compared to $70 \%$ from higher socio-economic status. ${ }^{13}$ Research indicates that high levels of stress, low social support networks, and depression during pregnancy have a powerful negative effect on maternal functioning and infant developmental outcomes. ${ }^{14}$ Though the use of psychotropic medications during pregnancy raises concerns, there are data to support 
the use of certain antidepressants, including fluoxetine and the tricyclic antidepressants. As depression during pregnancy carries risk for both the mother and child, it is crucial to diagnose depression in this setting and to provide appropriate treatment strategies. ${ }^{15}$ To make a case for screening for depression during prenatal care, this study was conceptualized.

\section{SUBJECTS AND METHODS}

This study was conducted by the department of Psychiatry in collaboration with department of Gynaecology and Obstetrics (Unit II) of Abbasi Shaheed Hospital, Karachi, Sindh - Pakistan, from July 2003 to October 2003. Subjects were randomly selected from the out patients department (OPD). Seventy-five patients in second (14-26 weeks) and third trimester (27-40 weeks) of pregnancy were selected, presenting to OPD. Patients suffering from previous depressive episode or taking psychotropic or steroids were not included in the study. Patients were explained about the nature of study and consent was obtained to participate in the study. A questionnaire was administered to collect the data. A valid, reliable, economical screening tool, the Edinburgh postnatal depression scale (EPDS) was used to detect prenatal depression. ${ }^{16}$ This scale was developed in 1987 to act as a specific measurement tool to identify depression in new mothers and has been validated as an antenatal screening tool. ${ }^{17}$ This scale is a 10 item self-reporting scale. An individual can score maximum of thirty points. A cutoff score of 12 was used to identify depression. Chisquare test was applied to assess the relationship between depression and age, parity and trimester of pregnancy.

\section{RESULTS}

Out of seventy-five pregnant women interviewed, 19 were in the second trimester and 56 in the third trimester of pregnancy. Twenty-two were primigravida (having first pregnancy) and 16 were grandmultipara (having more than four children). Thirty-seven women had more than one or less than four children. Mean age of females was 26 years. In all patients, 26 (34.6\%) were found to have depression based on Edinburgh postnatal depression scale. Among these, 4 of19 (21\%) were in second and 22 of $56(39 \%)$ in third trimester. Six (27\%) primigravida and $8(50 \%)$ grand multipara were found depressed. On univariate analysis, only grandmultiparity was significantly associated with prenatal depression (Table I). In addition, older age at pregnancy (> 30 years $40 \%$ ) was also associated with depression in the prenatal stage. Third trimester was more difficult period in prenatal depression as $39.28 \%$ had prenatal depression in this study which is a considerable number of cases.
TABLE I:

ASSOCIATION OF DEPRESSION WITH AGE, PARITY AND TRIMESTER

\begin{tabular}{|l|ll|c|}
\hline \multicolumn{1}{|c|}{ VARIABLE } & $\begin{array}{l}\text { FREQUENCY OF } \\
\text { DEPRESSION }\end{array}$ & $\begin{array}{c}\text { P- } \\
\text { VALUE }\end{array}$ \\
\hline $\begin{array}{l}\text { AGE (in years) } \\
<20(n=16) \\
21-30(n=54)\end{array}$ & 6 & $(37.5 \%)$ & \\
$>30(n=5)$ & 8 & $(14.8 \%)$ & $>0.05$ \\
\hline $\begin{array}{l}\text { PARITY } \\
\text { Primigravida }(n=22)\end{array}$ & 6 & $(27.27 \%)$ & \\
Multigravida $(n=37)$ & 12 & $(32.43 \%)$ & $>0.05$ \\
Grand Multi $(n=16)$ & 8 & $(50.0 \%)$ & \\
\hline TRIMESTER & & & \\
Second (n=19) & 4 & $(21.05 \%)$ & $>0.05$ \\
Third (n=56) & 22 & $(39.28 \%)$ & \\
\hline
\end{tabular}

\section{DISCUSSION}

In this study, a relatively high frequency of prenatal depression in women was found. Similar figures have been reported from studies in West. A recent study at University of Michigan, USA which included nearly 3,500 Michigan women found that one in five pregnant women may experience symptoms of depression during pregnancy. ${ }^{18}$ There was no significant difference amongst depression within different age groups, parity and trimester of pregnancy which means that depression occurs irrespective of any of these variables and should be looked for in all prenatal clients. Twenty percent of the pregnant women in that study scored high on a standard survey of depression symptoms, but of those, only $13.8 \%$ were receiving any mental health counseling, drugs or other treatment, whereas in this study no woman was receiving treatment. Depressed mood during pregnancy has also been associated with poor attendance at antenatal clinics, substance misuse, and poor self care ${ }^{19-22}$ The usual psychiatric mood disorders could be accentuated in the prenatal period due to poor nutrition, substance abuse, and prenatal noncompliance. ${ }^{23}$ Studies of prenatal psychopathology have mostly examined prenatal mood as a predictor of postnatal depression. ${ }^{24}$ Watson, et al found that in $23 \%$ of those who had postnatal depression they started during pregnancy ${ }^{25}$. In this study, we found a much higher proportion of depression and no one received any treatment which means that there would be many more women with depression who are neglected and untreated for depression. Hence, these findings may be just a tip of the iceberg. In a study carried out by Sheila, the women ranged in age from 18 to 46 years, with an average age of 28.6 years, and were from diverse racial and ethnic back- 
grounds with about $73 \%$ White. They were, on average, about 25 weeks into their pregnancies, but gestation ages ranged from 3 to 41 weeks. ${ }^{26}$ Our results are comparable to this study with average age of 26 and more (22 cases) in third trimester. Innumerable studies across the world have shown high rates of prenatal depression. ${ }^{23,27-30}$ In this study, a high frequency of depression was found in pregnant women. There is need for further studies to determine associations with modifiable factors and means for identification of these depressed women with simple screening tools which can be used at primary care level. More research is needed in particular, to evaluate the treatment modalities in the prenatal and postnatal periods. The main limitation of this study was a small sample size i.e. only seventy-five subjects. There is also need to incorporate the evidence of poverty, education, family issues and adjustment problems in screening such population.

\section{CONCLUSION}

Prenatal depression is common in the second and third trimesters of pregnancy, and can occur at any age and parity. If we compare international figures, it is high time to start looking into the psychological issues of parturition. As this is very difficult time both for the woman as well as for her obstetrician, so, careful assessment is advisable and appropriate risks/ benefits should be considered, whether to treat this disorder or else. Offering treatment may be important for both the mother and the future well-being of the child and family.

\section{REFERENCES}

1. Lehtinen V, Joukamaa M. Epidemiology of depression: Prevalence, risk factors and treatment situation. Acta Psychiatrica Scand. 1994;377:710.

2. Christopher JL, Alan DL. edi. WHO Global Burden of Disease. USA, Harvard University Press; 1996.

3. Campagne DM. Screening depressive patients in pregnancy with the pregnancy mood profile. J Repro Med. 2003;48(10):813-7

4. Gadit AA. Pattern of mental health morbidity. J Coll Physicians Surg Pak. 2001;11(11):706-8.

5. Rabbani F, Raja F. The minds of mothers: maternal mental health in an urban squatter settlement of Karachi. J Pak Med Assoc. 2000;50(9):306-12.

6. Steiner M. Perinatal mood disorders: position paper. Psychopharmacology Bull. 1998; 34(3): 3016.

7. Khan RF, Khan UA, Ahmed W, Khan SJ. Common risk factors of anxiety and depression. Ann
King Edward Med Coll. 1999;5(3,4):220-1.

8. Bonari L, Bennett H, Einarson A, Koren G. Risks of untreated depression during pregnancy. Can Family Physician. 2004;50:37-9.

9. Ali BS, Rahbar MH, Naeem S, Tareen AL, Gul A, Samad L. Prevalence of and factors associated with anxiety and depression among women in a lower middle class semi-urban community of Karachi, Pakistan. J Pak Med Assoc. 2002;52 (11):513-7.

10. Ali BS, Amanullah S. Prevalence of anxiety and depression in an urban squatter settlement of Karachi. J Coll Physicians Surg Pak. 2000;10:4-6.

11. Abidi MA, Gadit AA. Liaison psychiatry and referral rates among hospitalized patients. J Coll Physicians Surg Pak. 2003;13(5):274-6.

12. Naeem S, Ali BS, Iqbal A, Mubeen S, Gul A. Spontaneous recovery from depression in women: a qualitative study of vulnerabilities, strengths and resources. J Pak Med Assoc. 2004;54(2):49-51.

13. Afridi M, Mashhood A. Anxiety, depression and stress among the husbands of obstetric cases at Karachi. J Pak Med Assoc. 1999;49(11):265-8.

14. Cunningham M, Zayas LH. Reducing depression in pregnancy: designing multimodal interventions. Social Work. 2002; 47(2): 114-23.

15. Nonacs R, Cohen LS. Assessment and treatment of depression during pregnancy: an update. Psychiatric Clin North Am. 2003;26(3):547-62.

16. Taj R, Sikander KS. Effects of maternal depression on breast-feeding. J Pak Med Assoc. 2003;53(1):8-11.

17. Zuckerman B, Amaro A, Bauchner $\mathrm{H}$, Cabral $\mathrm{H}$. Depressive symptoms during pregnancy: relationship to poor health behaviors. Am J Obstet Gynecol. 1989;160:1107-11.

18. Spinelli MG. Antepartum and postpartum depression. J Gender Specific Medicine. 1997;1(2): 33-6.

19. Hobfoll SE, Ritter C, Lavin J, Hulsizer MR, Cameron RP. Depression prevalence and incidence among inner-city pregnant and postpartum women. J Consultation Clinical Psychology. 1995;65: 445-453.

20. Spinelli MG. Antepartum and postpartum depression. J Gender Specific Medicine. 1998;1(2):33-6.

21. Hobfoll SE, Ritter C, Lavin J, Hulsizer MR, Cameron RP. Depression prevalence and incidence among inner-city pregnant and postpartum women. J Consultation Clinical Psychology. 1995; 65: 445-453. 
22. Watson JP, Elliott SA, Rugg AJ, Brough DI. Psychiatric disorder in pregnancy and the first postnatal year. Br J Psychiatry. 1984;144:453-462.

23. Cox JL, Connor Y, Kendell RE. Prospective study of the psychiatric disorders of childbirth. Br J Psychiatry. 1982; 140:111-117.

24. Cox J, Holden JM, Sagovsky R. Detection of postnatal depression: development of the Edinburgh postnatal depression scale. $\mathrm{Br} \mathrm{J}$ Psychiatry. 1987;150:782-86.

25. Wadwa PD, Sandman CA, Porto M, DunkelSchetter C, Garite U. The association between prenatal stress and infant birth weight and gestational age at birth: a prospective investigation. Am J Obstet Gynecol. 1993;69:858-65.

26. Sheila M, Heather F, Frederic C. Depression dur- ing pregnancy. J women's health. 2003;12 (4).

27. O'Hara MW, Neunaber DJ, Zekoski EM. Prospective study of postpartum depression: prevalence, course and predictive factors. J Abnormal Psychology. 1984;93:158-171.

28. Green MJ. Who is unhappy after childbirth? Antenatal and intrapartum correlates from a prospective study. J Reprod Infant Psychology. 1990; 8: 175-183.

29. Steiner M. Perinatal mood disorders: position paper. Psychopharmacology Bull.1998;34(3):301-6.

30. Warner R, Appleby L, Whitton A, Faraghen B. Demographic and obstetric risk factors for postnatal psychiatric morbidity. $\mathrm{Br} \mathrm{J}$ Psychiatry. 1996;168: 607-11.

\begin{tabular}{|l|}
\multicolumn{1}{|c|}{ AUTHOR AFFILIATION: } \\
Dr. M. Munir Hamirani (Corresponding Author) \\
Assistant Professor, Department of Psychiatry \\
Abbasi Shaheed Hospital \& \\
Karachi Medical \& Dental College (KMDC), \\
Karachi- Pakistan. \\
E-mail: mmham@yahoo.com \\
Prof. Azra Sultana \\
Department of Gynaecology and Obstetrics (Unit II) \\
Abbasi Shaheed Hospital \& KMDC, Karachi. \\
Dr. Zubeda Ibrahim \\
Resident Medical Officer, \\
Department of Gynaecology and Obstetrics \\
Abbasi Shaheed Hospital \& KMDC, Karachi. \\
Dr. Humaira Iqbal \\
Resident Medical Officer, \\
Department of Psychiatry \\
Abbasi Shaheed Hospital \& KMDC, Karachi. \\
Dr. Sarwat Sultana \\
Resident Medical Officer, \\
Department of Gynaecology and Obstetrics \\
Abbasi Shaheed Hospital \& KMDC, Karachi. \\
\hline
\end{tabular}

